\title{
The Influence of Cervical Cavity Shape on the Restoration Material Retention A finite element method study
}

\begin{abstract}
ANAMARIA FLORESCU, STEFAN MANEA, VIOLETA HANCU, ROXANA MANU*, CORNELIA FLORENTINA BICLESANU
Titu Maiorescu University of Bucharest, Faculty of Dentistry, Department of Dental Specialities, 67A, Gheorghe Petrascu Str, 031593, Bucharest, Romania
\end{abstract}

\begin{abstract}
Present study examines, by means of finite element method, the influence of cervical cavity shape on tensions distribution caused by occlusal overload of the teeth with abfraction lesion. Same force values are applied to four 3-D lower premolar finite element models, representing four different cavity shapes. An extracted lower premolar which presented an abfraction lesion has been used. The restoration was achieved by using ER adhesive systems and Giomers. The premolar was scanned and the resulting sections were processed and converted into a 3D digital format. Thus, a model of finite elements which presented a restored wedge-shaped cavity in the cervical dental area was obtained. Then, by modifying the shape and dimensions, there were created another 3 modified-shape cavities. Forces of different magnitudes (45$150 N)$, exerted at a 45 degree angle on buccal cusp, have been applied. A wedge-shaped cavity with a short occlusal side does not show tension in the cervical region, nor in the distal angle of the restoration up to a force of 100N. So, in order to increase the retention of the abfraction restoration, changing the shape of the cavity could be the treatment of choice. Clinical relevance In order to avoid costly and unethical research, by means of FEM, different shapes of cervical cavities were easily created and conditions that influence retention of abfraction restoration were tested.
\end{abstract}

Keywords: cavity shape, noncarious cervical lesions (NCCL), abfraction, finite element method (FEM)

The restoration of non-carious cervical lesions (NCCL) is a difficult one because of many factors, including sclerotic dentin, the occlusal overstress, the small thickness, or lack, of enamel at the cervical level, incorrect tooth-brushing techniques, nutritional habits, restorative materials properties, etc.

From a clinical point of view, the predominant NCCL forms are the V-shaped lesions or the wedge-shaped ones, characteristic of the abfractions or abrasions, as well as the concave, rounded/dish-like lesions which are characteristic of dental erosions [1-4].

The tensions resulting from occlusal overstress are distributed to the enamel, dentin and the restoration material (the composite resin, adhesive system) [5].This concentration of tensions at the cement-enamel junction (CEJ) [6] is responsible not only for the development of wedge-shape cervical lesions (abfraction), but also for the loss of restorations.

When restorative treatment is needed, it is not advisable to transform a wedge-shaped lesion into a concave lesion, with the aim to increase retention. Although this is clinically doable, a lot of healthy dental tissue would be sacrificed, and thus be in contradiction to the principles of the minimum invasive therapy.

Since the shape of the cavity may be a factor that would influence the restoration retention, modifying the abovementioned shape might favour long-term restoration retention.

According to P. Magne [7], performing research on patients may prove both costly and unethical, and, in order to avoid it, virtual models, as well as simulations, have gained their ever larger presence in live experiments or clinical trials.

The aim of the study is to compare, by means of the finite element method (FEM), the most comprehensive in vitro investigation method in restorative dentistry that allows for realistic simulations [8, 9], the levels of tension generated under the action of the same force values which are applied to four 3-D lower premolar finite element models, representing four different cavity shapes, as well as to simulate the conditions that might lead to the increase in the retention of the cervical restoration by sacrificing the least dental tissue.

Finite element method comprises analyzing stress, deformation and propagation of the fracture line in a structure. When a force is applied to a structure, deformation and stress arise, and if stresses are excessive and go beyond the elastic limit, can cause fractures in the materials [10].

Analysis by FEM is particularly useful in detecting risk areas, giving us the possibility to study the distribution of stresses and strains of a mechanically loaded structure [11].

\section{Experimental part}

For the study, a lower premolar extracted for periodontal reasons was used; it presented an abfraction with a smooth, hard, shiny surface, without any carious process. The premolar was kept in physiological serum for 24 hours, then in T chloramine until the time of the experiment. The tooth was cleaned with a rubber cup and abrasive paste (Clean Polish, Kerr). A superficial dentin layer was removed and the edges were smoothed by means of a round burs (RA 1, Dia Tessin) on low speed.

Restoration was achieved using etch and rinse (ER) 3step adhesive systems (Gluma Solid Bond, Heraeus Kulzer) and Giomers (Beautifil low flow F02 and Beautifil II, Shofu Dental Corporation), whose compositions are shown in table $1[12,13]$.

\footnotetext{
* email: roxanamanu2012@yahoo.com; Phone +40745907021
} 
Table 1

MATERIAL COMPOSITION

\begin{tabular}{|c|c|}
\hline Material & Composition \\
\hline $\begin{array}{l}\text { Gluma Solid Bond, Heraeus Kultzer } \\
\text { (Adhesive system) }\end{array}$ & Bis-GMA, TEGDMA, HEMA, 25 filler $\%$ \\
\hline Beautifil FO2, Shofu Dental Corporation & $\begin{array}{l}\text { Base resin: Bis-GMA/TEGDMA resin } \\
\text { Filler: multi-functional glass filler, improved S-PRG } \\
\text { fillers based on fluoro-boraluminosilicate glass; } \\
\text { Filler loading: } 54.5 \mathrm{wt} \%, 34.6 \mathrm{vol} \% \text {; } \\
\text { Particle size range: } 0.01 \text { to } 2.0 \mu \mathrm{m} \\
\text { Mean particle size: } 0.8 \mu \mathrm{m}\end{array}$ \\
\hline Beautifil II, Shofu Dental Corporation & $\begin{array}{l}\text { Base resin: Bis-GMA/TEGDMA resin } \\
\text { Filler: multi-functional glass and S-PRG filler based on } \\
\text { fluoro-boraluminosilicate glass; } \\
\text { Filler loading: } 83.3 \mathrm{wt} \%, 68.6 \mathrm{vo} \% \text {; } \\
\text { Particle size range: } 0.01-4.0 \mu \mathrm{m} \\
\text { Mean particle size: } 0.8 \mu \mathrm{m}\end{array}$ \\
\hline
\end{tabular}

Table 2

REQUIRED CONSTANT DATA

\begin{tabular}{|c|c|c|c|c|}
\hline Material & $\begin{array}{c}\text { Elastic modulus } \\
(\mathrm{GPa})\end{array}$ & Poisson Ratio (v) & Yield Stress (MPa) & $\begin{array}{c}\text { Tensile strength } \\
(\mathrm{MPa})\end{array}$ \\
\hline Enamel & 80.35 & 0,33 & 24 & - \\
\hline Dentin & 19.89 & 0,31 & - & $90^{\circ}$ \\
\hline Pulp & 0.02 & $0,45^{-}$ & - & - \\
\hline Periodontal ligament & 0,0689 & 0,45 & - & - \\
\hline Cortical bone & 13,7 & 0.30 & - & - \\
\hline Spongious bone & 1,37 & 0,30 & - & - \\
\hline Gluma Solid Bond & 4 & 0,35 & 25 & 26 \\
\hline $\begin{array}{c}\text { BeatifilFO2 (low } \\
\text { flow) }\end{array}$ & $8.4^{-}$ & 0.35 & - & 119 \\
\hline Beautifil II & 11 & $0.35^{--}$ & 130 & 51 \\
\hline
\end{tabular}

The premolar was scanned by means of the Micro CT, while the resulting $0.5 \mathrm{~mm}$-wide longitudinal and transversal sections were processed by means the DICOM software. The scanned images were converted into a 3D digital format by means of the MIMICS software and processed in Abaqus /CAE in order to be analysed through the finite element method.

Thus, a model of finite elements which presented a restored wedge-shaped cavity in the cervical dental region (model 1) was obtained, while the necessary data was taken from available literature [12-16] (table 2).

On this finite elements model, by modifying the shape and dimensions, as shown in figure 1, there were created another 3 modified-shape cavities.

A wedge-shaped cavity with a very rounded axial angle was created on the second model.

On the $3^{\text {rd }}$ and $4^{\text {th }}$ models, wedge-shaped cavities with unequal sides were made, with the cervical side longer than the occlusal side on the $3^{\text {rd }}$ model, thus making an 80 degree angle with the long dental axis; at the same time, on the $4^{\text {th }}$ model, the cervical side was shorter than the occlusal one and perpendicular to the long axis of the tooth. In the end, the 4 premolar finite elements models with 4 different types of cavities are presented (fig. 1).

In the case of a functional occlusion, there is a vertical stress on the lateral side of the arch; the average occlusal force is $100 \mathrm{~N}$, but it may vary between 70 and $150 \mathrm{~N}$ [17]. At the same time, this force may vary according to the exact position of the tooth in the arch, the gender of the patient, the type of tooth (the force has a low value with the incisors and a maximum with the first molar) [18].

Occlusal forces generated during oral functions, nonfunction and premature contacts give rise to significant tensile stresses in the cervical enamel [14].

In order to simulate the most dangerous effects on a restored tooth, forces of different magnitudes were exerted on these models at a 45 degree angle and applied mainly 


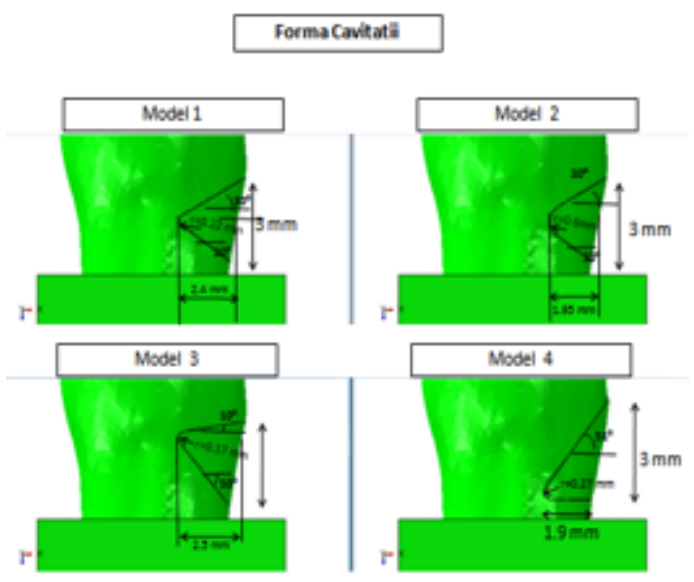

Fig. 1 Shapes and dimensions of cavities

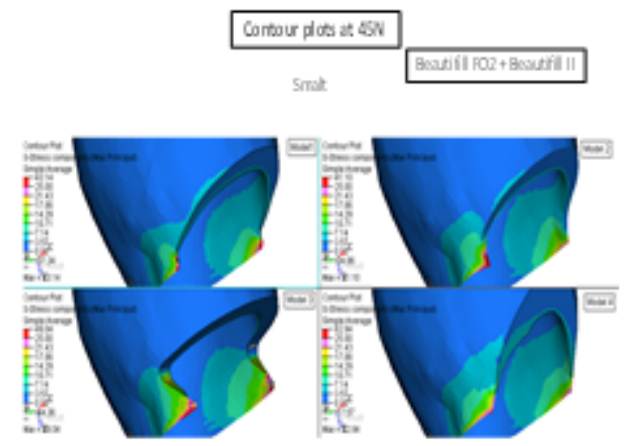

Fig. 2 The appearance of the first enamel fissure at a $45 \mathrm{~N}$ force

to the premolar buccal cusp. The values of the forces applied were: $45 \mathrm{~N}, 60 \mathrm{~N}, 90 \mathrm{~N}, 105 \mathrm{~N}, 120 \mathrm{~N}, 150 \mathrm{~N}$.

The tested forces, within functional occlusion, do not produce dental modifications, but, when applied at 45 degree angle, they create non-functional conditions, permitting an actual simulation of overstrain.

\section{Results and discussions}

When a $45 \mathrm{~N}$ force is tested, the first enamel fissure, located in the distal angle of lesions, may appear on models 1,2 and 4 . Tension levels are different depending on the shape of the cavity, high tension levels being observed on these models. On the $3^{\text {rd }}$ model, the same force generates tensions located in an area under the lesions distal angle, towards the cervical region of the tooth (fig.2).

The fissure development and the increases of tensions can be observed as a result of increasing the force to $60 \mathrm{~N}$. In all models, fissures have the tendency to evolve towards the cervical area (fig. 3).

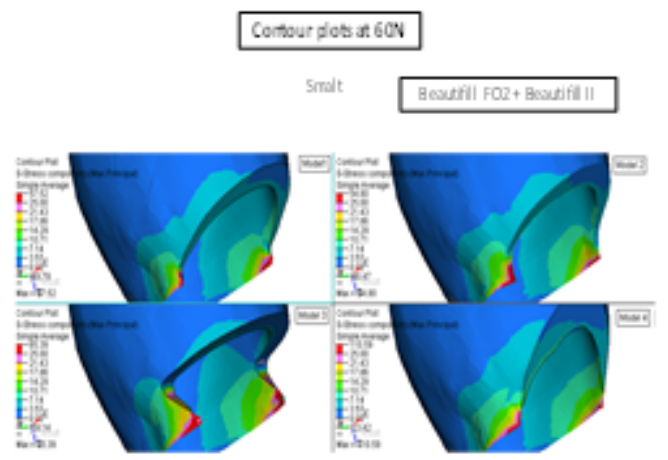

Fig. 3 Evolution of the crack on the enamel towards the gingival area at $60 \mathrm{~N}$
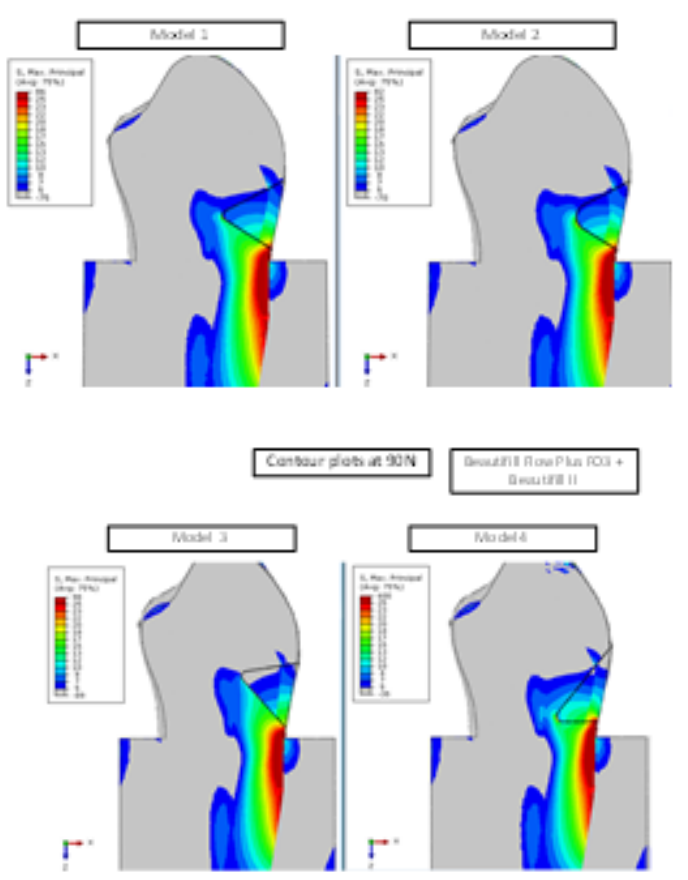

Fig.4 Tension distribution in distal angles of restorations for the models at $90 \mathrm{~N}$

At $90 \mathrm{~N}$ force, distal and mesial angles of restorations belonging to models 1,2 and 4 showed very low and low tension levels, while the 3rd model presented the lowest tension in the distal angles of restorations and increased tension level in the mesial angle of the restorations. These differences are probably due to the asymmetry of the tooth and to the differences between giomer's and dentin's composition and properties. Also, an accumulation of tensions can be observed on the cervical side of models 1 , 2 , and 4 as well; they affect both the tooth and the restoration. With this value of the force, the cervical tensions affect only the tooth, and not the restoration in the case of model 3 (fig. 4).

By increasing the force to $100 \mathrm{~N}$, highest level of tension concentrated in the cervical region of the restorations is observed for model 4and the lowest level for model 3. Models 1 and 2 show similar tension levels (fig. 5).

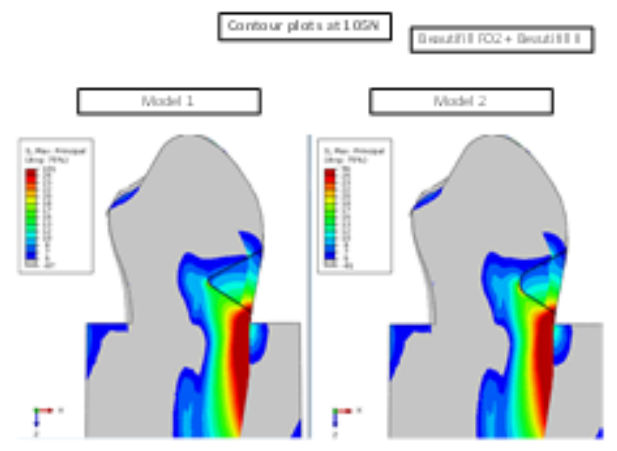

Fig. 5 Models with tension distribution at distal angles at $100 \mathrm{~N}$ 

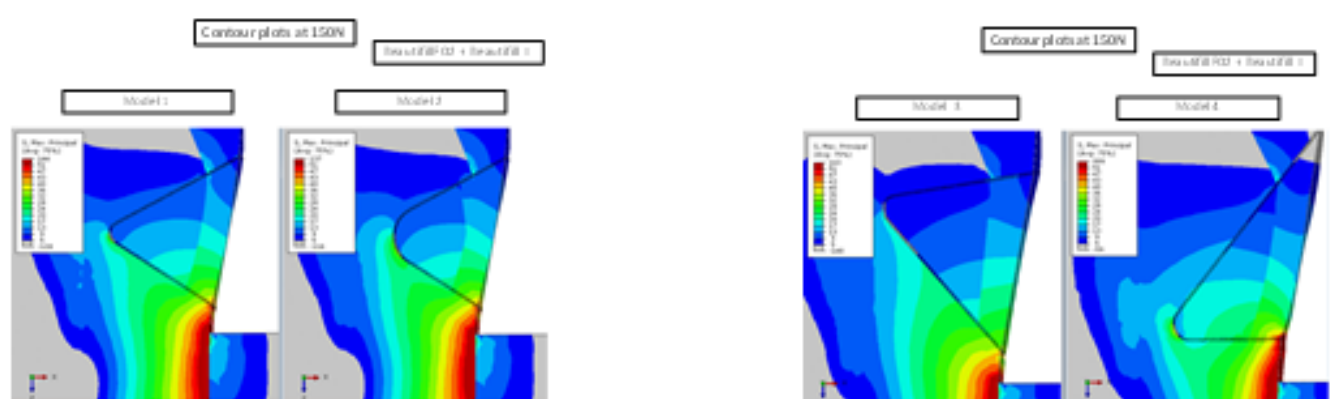

Fig.6 Tension distribution for models at $150 \mathrm{~N}$ (distal angle of the restoration)

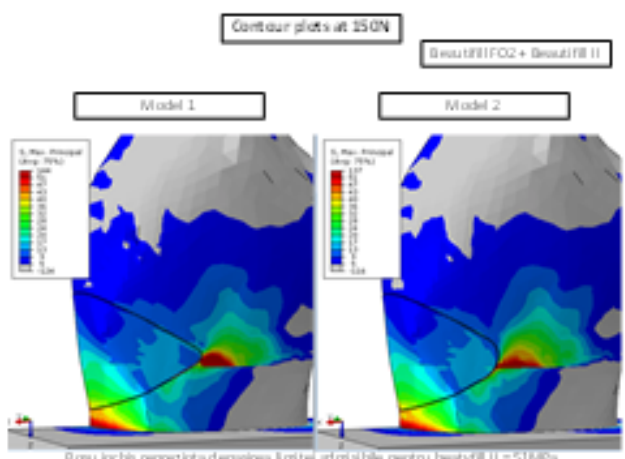

At $150 \mathrm{~N}$, the observed tensions maintain the same pattern in all 4 models (fig. 6); high tension levels have been observed in the cervical region of models 1,2 and 4 , except for model 3, who showed the highest tension concentration in its restoration mesial angle (fig. 7).

The aim of the study was to compare, by means of the finite element method (FEM), the levels of tension generated under the action of the same force values which are applied to four 3-D lower premolar finite element models, representing four different cavity shapes, as well as to simulate the conditions that might lead to the increase in the retention of the cervical restoration by sacrificing the least dental tissue.

For models with wedge-shaped cavity (model 1 ), rounded wedge tip (model 2) and the wedge with a shorter cervical side (model 4), at a $45 \mathrm{~N}$ force, a tension concentration in the distal angle of the restoration and the appearance of the first fissures in the enamel are observed. At a higher force of $60 \mathrm{~N}$, the evolution of the fissure towards the cervical margin of the restoration is observed. For the same models, at 90N, due to the difference in tension between dentin and Giomer, lower tension levels are observed in distal angles of the restoration; likewise, mild tension in the cervical region appears.

At $100 \mathrm{~N}$, the highest tension concentration is recorded if there is a wedge-shaped cavity with a short cervical side (model 4) and the lowest tension concentration appears in wedge-shaped cavity with a short occlusal side (model 3).

For wedge-shaped cavities with a short occlusal side (model 3), there is a tension concentration on the mesial angle of the restoration only at $90 \mathrm{~N}$, the level is greater than those of other models. Otherwise, the wedge-shaped cavity with a short occlusal side does not show tension in the cervical region, nor in the distal angle of the restoration up to a force of $100 \mathrm{~N}$. At $120 \mathrm{~N}$, the restorations exceed the permitted adhesive tension and therefore may detach.

Presence of high stress concentration in the mesio-axial and disto-axial proximities of Class $\mathrm{V}$ lesion was also reported by Shubhashini [19] when tensile load was applied on that tooth. The stress concentration is in the immediate vicinity of the restored area and was also found to be inversely proportional to the Young's modulus value of the restorative material used [19].

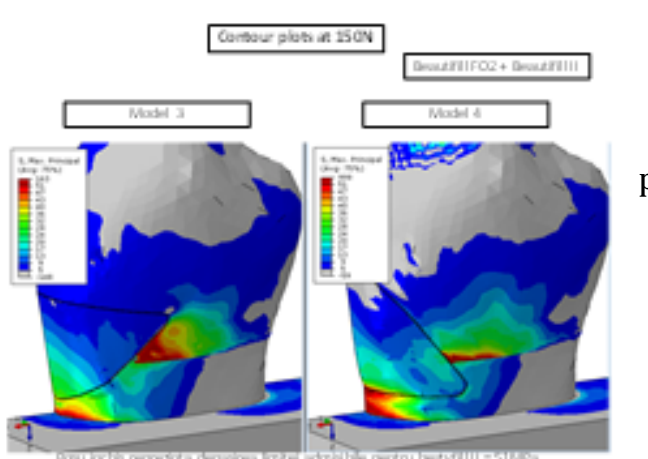

Fig. 7 Tension pressure distribution for models at $150 \mathrm{~N}$ (mesial angle of the restoration)

Although the dish-like cavity shows a much more favourable retention for NCCL restorations than wedgeshaped cavities do, as shown by E. Eliguzeloglu [20], the transformation of a wedge-shaped lesion into a rounded lesion requires a great sacrifice of healthy tooth tissue, which is often not accepted by the patient, and also contradicts the principles of minimal invasive therapy.

Turning a wedge-shaped cavity into a wedge-shaped cavity with a shorter occlusal wall (a minimally invasive manoeuvre in comparison with creating a rounded shaped cavity), and restoration with Giomers could be measures taken in order to increase the dental abfraction restoration retention.

\section{Conclusions}

Changing the shape of the cervical cavity through minimally invasive treatments along with Giomer direct adhesive restoration could be the best choice of noncarious lesions treatment with long term results.

AcknowledgementAuthors want to acknowledge the support of Stefan Cristian Castravete, General Manager, CAELYNX Europe.

\section{References}

1.ADDY, M., EMBERY, G., EDGAR, M., ORCHARDSON, R., Tooth Wear and Sensitivity- Clinical advances in restorative dentistry, ${ }^{\text {st }}$. edition, Ed. Martin Dunitz Ltd., Martin Dunitz Publishers, London ; 2000, p.376, p. $77-238$

2.GRIPPO, J., J Am Dent Assoc., 135, no. 10, 2004, p.1376;

3.BARTLETT, D., SHAH, P. A., J Dent Res., 85, 2006, p.306;

4.LUSSI, A., Dental Erosion-From Diagnosis to Terapy. Monographs in Oral Science, Karger Publishers, Basel, editor GM Whitford, 20, 2006, p. 3, p.10, p. 23;

5.VAN MEERBEEK, B., BRAEM, M., LAMBRECHTS, P., VANHERLE, G., Journal of Prosthetic Dentistry, 70, 1993, p.308;

6.ROMEED, S.A., MALIK, R., DUNNE, S.M., Int] Dent., 30; $2012: 234845$. Epub 2012 Jul 30;

7.MAGNE, P., Dent Mat., 23, nr. 5, 2007, p.539;

8.TANTBIROJN, D., VERSLUIS, A., PINTADO, M.R., DELONG, R., DOUGLAS, W.H., Dent Mater., 20, 2004, p.535;

9.VERSLUIS, A., TANTBIROJN, D., PINTADO, M.R., DELONG, R., DOUGLAS, W.H., Dent Mater., 20, 2004, p. 554;

10.COMAN, C., GHERGIC, D.L., PATROI, D.N., TARCOLEA, M., COMANEANU, R.M., BARBU, H.M., Mat. Plast.,53, no.1, 2016, p. 91 
11.ORMENISAN, A., TARCOLEA, M., SUCIU, M., GRIGORAS, R.I., BERESESCU, F.G., VLASCEANU, D., HANCU, V., COMANEANU, R.M., Mat. Plast., 52, no. 3, 2015, p. 373

12.*** www.giomer.com

13.*** www.heraeus-kulzer.com

14.ROMEED, S.A., FOK, S.L., WILSON, N.H., Journal of Oral Rehabilitation., 33, 2006, p. 209;

15.POIATE, I .A.V.P. et al., Brazilian Oral Research 23, nr.2, 2009, p.161; 16.KIM, K.-H., WOO, S.-G., SON, K., PARK, J.-K., Proceedings of the $18^{\text {th }}$ IASTED International Conference Modelling and Simulation, 2007, Montreal, Quebec, Canada;
17.MOTTA, A.B., PEREIRA, L.C., DA CUNHA, A.R.C.C., ABAQUS Users' Conference, 2006, p.329;

18.FERRARIO, V. F., SFORZA, C., SERRAO, G., DELLAVIA, C., TARTAGLIA, G.M., J Oral Rehab., 31, nr.1, 2004, p.18;

19.SHUBHASHINI, N., MEENA, N., SHETTY, A., KUMARI, A., NAVEEN, D.N., J Conserv Dent., 11, no. 3, 2008, p. 121;

20.ELIGUZELOGLU, E., ERASLAN, O., OMURLU, H., ESKITASCIOGLU, G., BELLI, S., European Journal of Dentistry, 5, 2011, p. 180

Manuscript received: 12.08 .2016 